\title{
GDF-15 plasma levels in chronic obstructive pulmonary disease are associated with subclinical coronary artery disease
}

Carlos H. Martinez', Christine M. Freeman 1,2, Joshua D. Nelson', Susan Murray ${ }^{3}$, Xin Wang ${ }^{3}$, Matthew J. Budoff', Mark T. Dransfield ${ }^{5,6}$, John E. Hokansonn ${ }^{7}$, Ella A. Kazerooni ${ }^{8}$, Gregory L. Kinney ${ }^{7}$, Elizabeth A. Regan, ${ }^{9}$, J. Michael Wells ${ }^{5,6}$, Fernando J. Martinez ${ }^{11}$, MeiLan K. Han ${ }^{1}$, Jeffrey L. Curtis ${ }^{1,12,13^{*}}$ and for the COPDGene Investigators

\begin{abstract}
Background: Growth differentiation factor-15 (GDF-15), a cytokine associated with cardiovascular mortality, increases during chronic obstructive pulmonary disease (COPD) exacerbations, but any role in stable COPD is unknown. We tested associations between GDF-15 and subclinical coronary atherosclerosis, assessed by coronary artery calcium (CAC) score, in COPD subjects free of clinical cardiovascular disease (CVD).

Methods: Cross-sectional analysis of COPD participants (GOLD stages 2-4) in the COPDGene cohort without CVD at enrollment, using baseline CAC (from non-EKG-gated chest computed tomography) and plasma GDF-15 (by custom ELISA). We used multinomial logistic modeling of GDF-15 associations with CAC, adjusting for demographics, baseline risk (calculated using the HEART: Personal Heart Early Assessment Risk Tool (Budoff et al. 114:1761-1791, 2006) score), smoking history, measures of airflow obstruction, emphysema and airway disease severity.

Results: Among 694 participants with COPD (47\% women, mean age 63.6 years) mean GDF-15 was 1,304 pg/mL, and mean CAC score was 198. Relative to the lower GDF-15 tertile, higher tertiles showed bivariate association with increasing CAC score (mid tertile odds ratio [OR] 1.80, 95\% confidence interval [CI] 1.29, 2.51; higher tertile OR 2.86, Cl 2.04, 4.02). This association was maintained after additionally adjusting for baseline CVD risk, for co-morbidities and descriptors of COPD severity and impact, markers of cardiac stress (N-terminal pro-B-type natriuretic peptide, troponin $\mathrm{T}$ ) and of inflammation (Interleukin-6), and in subgroup analysis excluding men, diabetics, current smokers or those with limited ambulation.
\end{abstract}

Conclusions: In ever-smokers with COPD free of clinical CVD, GDF-15 contributes independently to subclinical coronary atherosclerosis.

Trial registration: ClinicalTrials.gov, NCT00608764. Registered 28 January 2008.

Keywords: Adult, Biomarkers, Coronary Artery Disease, Cross-Sectional Studies, Multivariate Analysis, Risk Factors

\footnotetext{
*Correspondence: jlcurtis@umich.edu

'Division of Pulmonary \& Critical Care Medicine, University of Michigan

Health System, 2215 Fuller Road, Ann Arbor, Ml 48105-2303, USA

${ }^{12}$ Graduate Program in Immunology, University of Michigan, 2215 Fuller

Road, Ann Arbor, MI 48105-2303, USA

Full list of author information is available at the end of the article
} 


\section{Background}

In chronic obstructive pulmonary disease (COPD), cardiovascular disease (CVD), especially coronary heart disease (CHD), is highly prevalent and impacts mortality and quality of life [1]. COPD is linked to increased risk of overt CVD by substantial epidemiological data, including three large population-based cohorts, two primary care databases, and the nationally representative NHANES survey [1-5]. Uniquely among leading causes of death, worldwide COPD prevalence continues to increase $[6,7]$, especially among women [8]. Hence, gains in controlling CHD mortality may stall unless the independent contribution from COPD can be combated.

Shared risk factors only partially explain this association between COPD and CHD [9, 10]. Its molecular basis remains undefined, particularly for subclinical disease, the logical window for prevention. One early CHD marker is subclinical coronary artery calcium (CAC), defined as CAC in those free of clinical CVD. CAC is a validated surrogate measure that predicts future cardiovascular events and mortality $[11,12]$.

Growth-differentiation factor-15 (GDF-15) (gene ID 9518) is a cytokine of the transforming growth factor- $\beta$ family associated with endothelial and left ventricular dysfunction [13]. Elevated GDF-15 is linked to cardiovascular and all-cause mortality in older adults $[14,15]$. We and others recently identified elevated GDF-15 during early COPD exacerbations [16-18].

We hypothesized that in COPD, GDF-15 contributes significantly to subclinical CHD presence and severity as determined by $\mathrm{CAC}$, independently of established CVD risks. We tested this hypothesis using participants with COPD in a well-characterized cohort who were without clinical CVD history and $>30$ days from exacerbation. Because COPD is heterogeneous [19], with co-morbidity clustering with specific phenotypes [20,21], we also examined associations with imaging-defined phenotypes.

\section{Methods}

\section{Study design}

This cross-sectional analysis used baseline data from the Genetic Epidemiology of COPD Study (COPDGene ${ }^{\circ}$ ) (ClinicalTrials.gov \# NCT00608764), an ongoing multicenter observational cohort designed to identify genetic factors in smoking-related lung disease [22]. COPDGene recruited ever-smokers ( $\geq 10$ pack-year), non-Hispanic White or African American adults, both sexes, who underwent a detailed phenotypic evaluation, including highresolution chest computed tomography (HRCT).

\section{Ethics, consent and permissions}

Studies and consent procedures were performed in accordance with the Declaration of Helsinki. Participants understood the study purpose, and provided written informed consent before any procedures. Protocols were approved by Institutional Review Boards at VA Ann Arbor Healthcare System (FWA 00000348) and the University of Michigan (FWA 00004969), approval numbers 2010-120752, HUM000014973, respectively, where we conducted laboratory and statistical analysis, respectively, and at all participating clinical sites.

\section{Study participants}

Participants were chosen from a biomarker pilot project (original $n=1000$, balanced for sex, age, and equivalent numbers in GOLD stages 2-4), by selecting subjects with available CAC scores and without self-reported CVD. We diagnosed COPD using the fixed-ratio definition [23] (postbronchodilator forced expiratory volume in the first second over forced vital capacity [FEV1/FVC] ratio $<0.7$, plus GOLD grade $2-4$ obstruction (FEV1\% predicted $<80 \%$ ). Spirometry was performed using an EasyOne ${ }^{\mathrm{ma}}$ spirometer and NHANES III predictions [24]. Participants were CHDfree on enrollment, based on negative answers to questions about physician diagnosis ("Have you ever been told by a physician that you have...") of heart attack, myocardial infarction, coronary artery disease. We also excluded subjects reporting coronary angioplasty or bypass grafting, congestive heart failure, stroke, transient ischemic attacks or peripheral vascular disease.

\section{Data collection \\ Outcome}

We scored CAC following Agatston's algorithm [25, 26], from HRCT imaging, un-gated for EKG, and stratified into categories of $0,1-100,101-400$ and $>400$ Agatston Units (absence of CAC, mild/minimal, moderate and extensive plaque burden, respectively) [27]. The accuracy and reliability of CAC scoring using un-gated HRCT has been validated in comparisons with EKG-gated studies in COPDGene participants [28].

\section{Exposure}

We measured GDF-15 levels by ELISA according to manufacturer's instructions from plasma collected at enrollment and stored at $-80{ }^{\circ} \mathrm{C}$ until analyzed in duplicate; values are presented in $\mathrm{pg} / \mathrm{mL}$; the lower limit of detection is $2 \mathrm{pg} / \mathrm{mL}$.

\section{Covariates}

Demographics, smoking and medical history were collected using self-administered questionnaires. Co-morbidities and risk factors were ascertained by combining responses to questions on physician-based diagnosis and review of current medications. We considered hypertension, hyperlipidemia and diabetes present when the participant reported either diagnosis or current medication use for that disease. Physical activity was considered limited based on 
affirming "Was your walk limited?" during a 6-min walk test. We calculated 10-year CHD risk based on Personal Heart Early Assessment Risk Tool (HEART score) [25], a validated assessment based on self-reported data [29] suitable for use in subjects without previous CHD diagnosis and in the public domain.

We obtained emphysema percentage and airway wall thickness from volumetric HRCTs obtained at full inflation [22], using 3D Slicer software (www.Slicer.org) and a VIDA Pulmonary Workstation, respectively. Lung areas $<-950$ Hounsfield Units were considered emphysema, which we stratified as below or $\geq 10 \%$ of lung volume. Airway metrics included the square root of the wall area of a theoretical airway of $10 \mathrm{~mm}$ luminal perimeter (Pi10).

\section{Additional plasma analytes}

We measured troponin T, N-terminal-proBNP and IL-6 on the same samples using Luminex assays from Milliplex MAP Human Cardiovascular Disease Panels (EMD Millipore, Billerica, Massachusetts). Assays were run in duplicate according to manufacturer's instructions. The lower limits of detection were $9 \mathrm{pg} / \mathrm{mL}, 18.8 \mathrm{pg} / \mathrm{mL}$ and $0.2 \mathrm{pg} / \mathrm{mL}$, respectively.

\section{Statistical analysis}

Demographics, smoking history, lung function and cardiovascular risk were analyzed by GDF-15 tertiles, using $t$-test or chi-square. We tested association between GDF-15 tertiles and CAC burden categories by two strategies. First, we used regression models with CAC as outcome. Second, we developed sequential multinomial logistic regression models including variables grouped in bloc, starting with GDF tertiles, then adjusting for baseline HEART score, then further adjusting for co-morbidities, measures of lung function, and severity of airway disease and emphysema. We selected logistic modeling as our main approach because it presents outcome and exposure as categories, rather than numeric values, improving their interpretability and clinical relevance. We tested interactions of GDF-15 with imaging characteristics and lung function using similar models. Analyses were performed using Prism 6.0f (GraphPad Software, Inc; La Jolla, CA) and Stata v.12 (College Station, TX).

\section{Results}

We included 694 subjects free of clinical CVD, with large proportions of women and those with chronic bronchitis and $>50$ pack-years smoking history (Table 1 ). Almost half were considered at low cardiovascular risk (10 year CHD risk $<10 \%)$ by HEART score. As a group, men had significantly higher CAC scores $(p<0.0001)$ (Fig. 1a) and GDF-15 levels ( $p=0.007)$ (Fig. 1b).

As anticipated, there was a correlation between GDF-15 levels and $\log _{2}$ CAC that was modest $\left(r_{S}=0.2693\right.$;
$\left.\mathrm{R}^{2}=0.05982\right)$ but significant $(p<0.0001)$ (Fig. 2). Neither CAC nor GDF-15 correlated with pulmonary artery enlargement, as determined by the ratio of pulmonary artery and aorta diameters (PA:A ratio) [30] (Additional file 1: Table S1), implying that this association did not reflect occult pulmonary hypertension.

Comparing participants by GDF-15 tertiles, those in the higher tertile were significantly older, and more often men and non-Hispanic whites (Table 1). Additionally, high GDF-15 tertile participants had greater smoking histories, more frequently had diabetes, hypertension, hyperlipidemia and obesity, and were more frequently classified at intermediate or high risk by HEART score. However, there were no differences in measures of lung function, dyspnea or emphysema severity (Table 1).

In bivariate and multivariate analyses, GDF-15 levels (in tertiles) were associated with higher $\mathrm{CHD}$ risk by HEART score and by its components, including age, smoking and diabetes (Additional file 1: Table S2). Again, however, GDF-15 levels were not influenced by common descriptors of COPD severity (GOLD spirometry severity, FEV1, exacerbation history) or phenotypes (chronic bronchitis, measures of emphysema or airway thickness) (Additional file 1: Table S2).

With increasing GDF-15 tertiles, median CAC scores rose, both as absolute values (not shown) and after logarithmic transformation (Fig. 3). There was a stepped increase in CAC scores with increasing GDF-15: relative to the lower GDF-15 tertile, we found 1.19-fold and 2.10-fold increases, respectively, in mid- and highest tertiles. Nevertheless, even in the highest tertile, not all subjects had measurable CAC (Fig. 3).

In logistic models, GDF-15 contributed significantly to CAC burden (Table 2). The association of GDF-15 and CAC (by severity groups) was strong in the bivariate model (Model 1), and remained of similar magnitude after additionally adjusting for baseline cardiovascular risk (Model 2), for co-morbidities and measures of lung function (Model 3), and for biomarkers (Model 4). Importantly, the magnitude of the GDF-15-CAC association was at least as great as that of the combined classical risk factors included in the HEART score.

Next, we performed a sensitivity analysis, testing the association in subgroups chosen to minimize known correlation with CAC. First, we restricted analysis to women (Table 3). Second, we excluded those with diabetes, a major contributor to the HEART score that is associated with both CAC and GDF-15 elevation. Third, we restricted analysis to those not smoking at enrollment. Fourth, because low physical activity and a sedentary lifestyle are strong CVD risk factors, we repeated the analysis using only those reporting no walking limitations. None of these preplanned subgroups analysis significantly modified the association of GDF-15 (higher tertile) with CAC (Table 3). 
Table 1 Characteristics of COPDGene participants with COPD, by GDF-15 tertiles

\begin{tabular}{|c|c|c|c|c|c|}
\hline & $\begin{array}{l}\text { All participants } \\
(n=694)\end{array}$ & $\begin{array}{l}\text { Lower }(\leq 966 \mathrm{pg} / \mathrm{mL}) \\
(n=231)\end{array}$ & $\begin{array}{l}\text { Mid }(967-1438 \mathrm{pg} / \mathrm{mL}) \\
(n=232)\end{array}$ & $\begin{array}{l}\text { Higher }(\geq 1439 \mathrm{pg} / \mathrm{mL}) \\
(n=231)\end{array}$ & $p$-value \\
\hline \multicolumn{6}{|l|}{ Sociodemographics } \\
\hline Age (mean, s.d.) & $63.6(8.4)$ & $59.7(7.4)$ & $64.6(8.1)$ & $66.4(8.3)$ & $<0.001$ \\
\hline Females (\%) & 47.1 & 49.4 & 52.6 & 39.4 & 0.01 \\
\hline African American (\%) & 16.3 & 21.7 & 13.8 & 13.4 & 0.02 \\
\hline BMI (mean, s.d.) & $27.3(6.0)$ & $27.5(6.0)$ & $26.8(5.7)$ & $27.6(6.2)$ & 0.31 \\
\hline \multicolumn{6}{|l|}{ Respiratory status } \\
\hline $\mathrm{FEV}_{1}$ in $\mathrm{L}$ (mean, s.d.) & $1.25(0.64)$ & $1.28(0.69)$ & $1.20(0.61)$ & $1.26(0.60)$ & 0.30 \\
\hline FEV 1 \% predicted (mean, s.d.) & $43.5(18.8)$ & $42.9(19.3)$ & $42.9(18.6)$ & $44.7(18.4)$ & 0.50 \\
\hline $\mathrm{FEV}_{1} / \mathrm{FVC} \%$ (mean, s.d.) & $44.4(13.6)$ & $44.2(13.8)$ & $43.9(13.5)$ & $45.4(13.6)$ & 0.45 \\
\hline \multicolumn{6}{|l|}{ GOLD stage (\%) } \\
\hline$\|$ & 34.1 & 31.6 & 33.2 & 37.7 & \\
\hline III & 33.6 & 32.9 & 35.8 & 32.0 & \\
\hline IV & 32.3 & 35.5 & 31.0 & 30.3 & 0.55 \\
\hline mMRC dyspnea score (mean, s.d.) & $2.3(1.4)$ & $2.3(1.4)$ & $2.2(1.4)$ & $2.3(1.4)$ & 0.48 \\
\hline Pack-years smoked (mean, s.d.) & $52.2(25.3)$ & $47.8(23.6)$ & $52.0(24.2)$ & $56.8(27.3)$ & $<0.001$ \\
\hline Six-minute walking distance, in f. (mean, s.d.) & $1163(395)$ & $1221(395)$ & $1180(377)$ & $1087(403)$ & 0.001 \\
\hline Chronic bronchitis (\%) & 27.0 & 26.4 & 26.7 & 27.7 & 0.94 \\
\hline Emphysema \% (mean, s.d.) & $17.1(14.4)$ & $18.2(14.7)$ & $17.1(14.2)$ & $16.0(14.2)$ & 0.26 \\
\hline Pi10 (mean, s.d.) & $3.73(0.14)$ & $3.72(0.14)$ & $3.71(0.13)$ & $3.75(0.14)$ & 0.04 \\
\hline \multicolumn{6}{|l|}{ Cardiovascular risk factors (\%) } \\
\hline $\mathrm{BMI} \geq 30$ & 29.0 & 28.1 & 26.3 & 32.5 & 0.32 \\
\hline Diabetes & 8.7 & 2.6 & 4.7 & 18.6 & $<0.001$ \\
\hline Currently smoking & 29.8 & 31.6 & 25.0 & 32.9 & 0.13 \\
\hline Hypertension & 43.8 & 34.6 & 46.1 & 50.7 & 0.002 \\
\hline Hyperlipidemia & 36.6 & 28.1 & 41.0 & 40.7 & 0.005 \\
\hline \multicolumn{6}{|l|}{ Aggregate 10-year coronary heart disease risk ${ }^{\mathrm{a}}(\%)$} \\
\hline Low $(<10 \%)$ & 44.5 & 56.3 & 47.0 & 30.3 & \\
\hline Intermediate (10\%-20\%) & 39.9 & 37.7 & 38.8 & 43.3 & \\
\hline High (>20\%) & 15.6 & 6.1 & 14.2 & 26.4 & $<0.001$ \\
\hline \multicolumn{6}{|l|}{ Other co-morbidities (\%) } \\
\hline GERD & 28.4 & 30.3 & 28.0 & 26.8 & 0.70 \\
\hline Asthma & 22.5 & 26.4 & 22.8 & 18.2 & 0.10 \\
\hline Osteoporosis & 15.9 & 13.4 & 17.2 & 16.9 & 0.46 \\
\hline Osteoarthritis & 15.0 & 13.0 & 13.8 & 18.2 & 0.24 \\
\hline Stomach ulcers & 8.4 & 10.4 & 8.2 & 6.5 & 0.31 \\
\hline
\end{tabular}

${ }^{a}$ Based on the HEART score, as described in the Methods section

Finally, we tested whether different markers of COPD phenotype and severity modified this association (Additional file 1: Table S3). Given correlations between airway thickness and cardiometabolic diseases [21], we used two approaches, restricting the analysis to those with less airway disease (lower two tertiles of pi10 distribution) or those with greater emphysema. We also restricted analysis to subjects with less severe airflow obstruction (defined either as spirometry stage $2-3$ or $\mathrm{FEV}_{1} \geq 1 \mathrm{~L}$ ). None of these analyses (Additional file 1: Table S3) changed the associations between GDF-15 and CAC.

\section{Discussion}

This analysis of 694 ever-smokers without clinical CVD at enrollment to the COPDGene cohort demonstrates that GDF-15 independently contributes to subclinical 

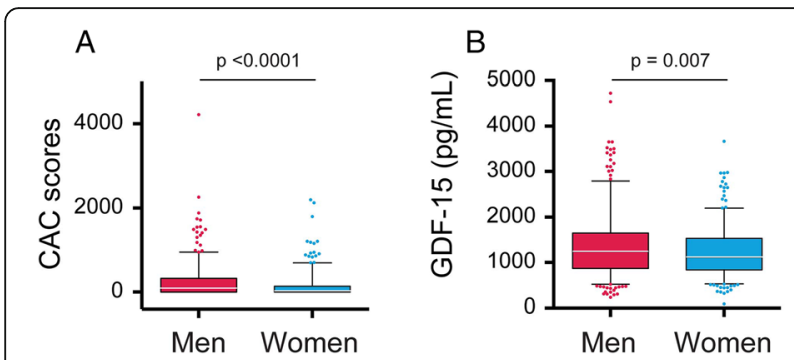

Fig. 1 CAC scores \& GDF-15 plasma levels by sex. CAC scores were determined by analysis of non-EKG-gated HRCT and GDF-15 plasma levels were measured by ELISA. a, CAC scores, as Agatston Units; b, GDF-15 concentrations, as pg/mL. Data are median (bar), 25th \& 75th percentiles (box), 5th \& 95th percentiles (whiskers) with outliers shown as individual points. $p$-values by Mann-Whitney test

atherosclerosis in COPD. Although GDF-15 is elevated in pulmonary hypertension of any cause, we found no correlation with PA:A ratio. The association of GDF-15 with CAC showed a gradient, and both its magnitude, and its persistence in subgroup analyses, imply that GDF-15 is not simply a surrogate for traditional risk factors. Instead, our findings support the concept [31] that adding GDF-15 to established indicators improves CVD risk estimation. This supposition, which will require additional testing, is most relevant to younger COPD subjects in low GOLD stages, in whom long-term CVD risk could exceed that of respiratory death. Thus, these data have important implications for reducing the impact of multi-morbidity in ever-smokers and also provide potential mechanistic insight into the link between COPD and overt CVD [1-5].

Reduced lung function as powerfully predicts CVD mortality as total cholesterol [32] but has never been embraced as a modifiable risk factor. Our findings are consistent with reported associations between smoking, airflow limitation and subclinical atherosclerosis, as measured by carotid intimal thickening [33]. We extend

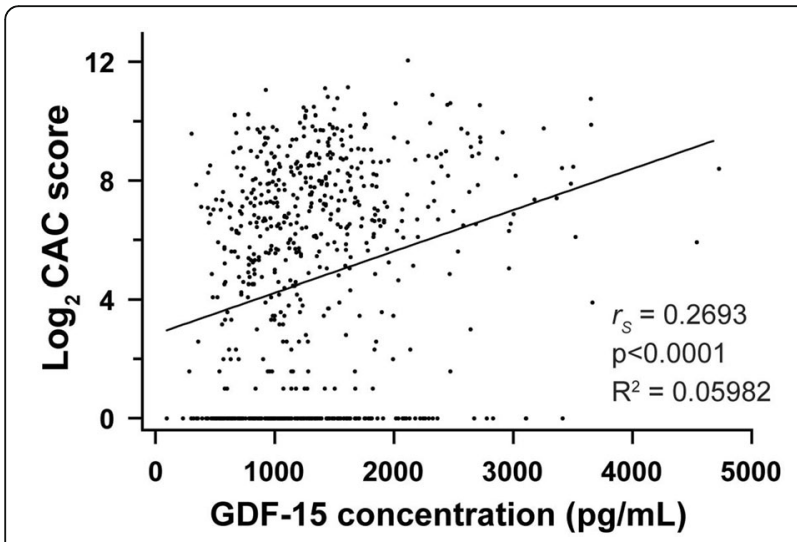

Fig. 2 Correlation between $\log _{2}$ CAC \& GDF-15 plasma concentrations. $p$-value by Spearman correlation $\left(r_{s}\right)$, goodness of fit $\left(R^{2}\right)$ by linear regression $(n=694)$

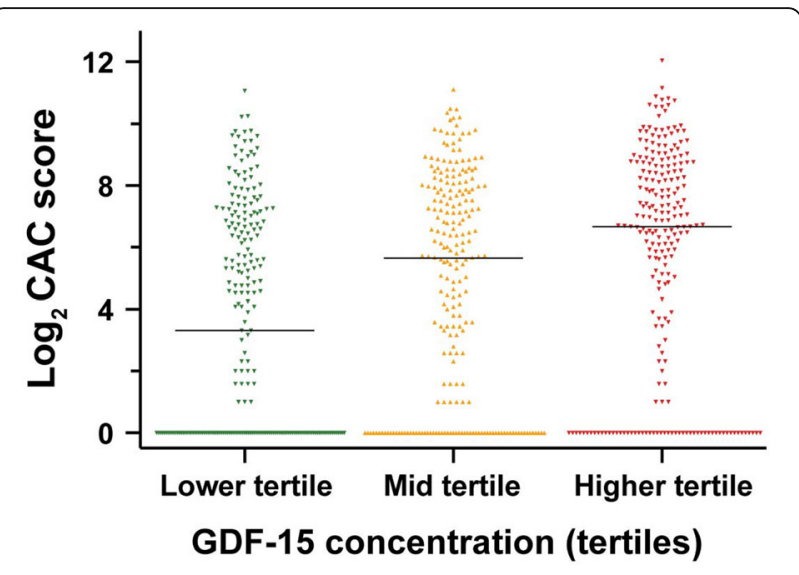

Fig. 3 Distribution of $\log _{2}$ CAC by GDF-15 tertiles. Lower tertile $(<966 \mathrm{pg} / \mathrm{mL})(n=231)$, mid tertile $(967-1438 \mathrm{pg} / \mathrm{mL})(n=232)$, higher tertile $(>1439 \mathrm{pg} / \mathrm{mL})(n=231)$

those results by using $\mathrm{CAC}$ score, which has higher predictive value for incident CVD than carotid plaque [34], and by showing independence from active smoking. That point is important, as GDF-15 is elevated by smoking [3] and cigarette smoke induces its production by human lung epithelial cells in vitro [35].

We extend to stable COPD without clinical CVD the evidence that GDF-15 is an informative biomarker, as established in overt CVD [36, 37]. To our knowledge, the only previous study that analyzed GDF-15 in stable COPD [38] found elevated levels relative to healthy never-smokers, but was underpowered $(n=15)$ to examine other correlations. Our findings agree with two large (combined $n=2395$ ) studies of community-dwelling elderly individuals without CVD history in showing that GDF-15 adds significant value to predictive models based on accepted CVD biomarkers $[14,15]$. Those longitudinal studies additionally found that baseline GDF-15 levels independently predicted all-cause and cardiovascular mortality [14, 39], which we hope to examine in our 694 COPDGene participants. Importantly, associations of GDF-15 with mortality in the general population equal or exceed that of $\mathrm{N}$-terminal pro-BNP and C-reactive protein $[14,15]$.

However, the clinical value of CAC is debated, and currently only recommended for selected asymptomatic adults at intermediate risk [40]. Data on CAC in COPD are conflicting. A single-center case-control study $(n=162)$ found no difference in CAC despite higher major adverse cardiovascular events in COPD [41]. By contrast, CAC on non-EKG-gated CTs correlated significantly with all-cause mortality in ECLIPSE, in an analysis including those with known CVD [27]. Interestingly, CAC scores in ECLIPSE did not correlate with $\mathrm{FEV}_{1}$ or exacerbation history. Similarly, we did not find a correlation of baseline GDF-15 levels and common markers of COPD severity 
Table 2 Adjusted associations of GDF-15 levels and of cardiovascular risk with CAC score among COPDGene participants with COPD $(n=694)$

\begin{tabular}{|c|c|c|c|c|}
\hline & Model $1^{a}$ & Model $2^{b}$ & Model $3^{c}$ & Model $4^{d}$ \\
\hline \multicolumn{5}{|l|}{ GDF-15 level (in tertiles) } \\
\hline Lower tertile & Ref. & Ref. & Ref. & Ref. \\
\hline Intermediate tertile & $2.52(1.10,2.71)$ & $2.30(1.19,4.44)$ & $2.16(1.11,4.20)$ & $1.87(0.88,3.99)$ \\
\hline Higher tertile & $5.70(3.08,10.56)$ & $4.53(2.40,8.54)$ & $4.22(2.20,8.07)$ & $4.28(2.09,8.76)$ \\
\hline \multicolumn{5}{|c|}{ Coronary heart disease risk group $^{e}$} \\
\hline Low (<10\%) & & Ref. & Ref. & Ref. \\
\hline Intermediate (10\%-20\%) & & $1.49(0.86,2.57)$ & $1.46(0.83,2.58)$ & $1.33(0.69,2.55)$ \\
\hline High (>20\%) & & $2.89(1.45,5.77)$ & $3.77(1.79,7.94)$ & $3.97(1.68,9.35)$ \\
\hline
\end{tabular}

All entries represent risk ratio of being in the higher group of CAC and its $95 \% \mathrm{Cl}$, based on multinomial logistic regression models, in which GDF-15 tertiles are compared again the lower tertile as reference, and the groups of cardiovascular risk by the HEART score are compared with the low-risk group as reference. ${ }^{a}$ Model 1: Bivariate. ${ }^{b}$ Model 2: Model 1 additionally adjusted for baseline coronary heart disease risk group. ${ }^{\mathrm{C}}$ Model 3 : Model 2 additionally adjusted for race, GOLD spirometry stage, pack-years smoked, chronic bronchitis symptoms, history of exacerbations, measures of emphysema and airway thickness, and comorbidities (asthma, GERD, mobility-related diseases). ${ }^{\mathrm{d}}$ Model 4: Model 3 additionally adjusted for N-terminal pro-B-type natriuretic peptide, troponin T and

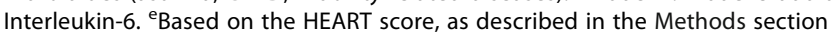

and phenotypes. Thus, GDF-15 appears to be a prognostic biomarker of CVD co-morbidity, but not a predictive biomarker of COPD outcomes, in agreement with recent findings suggesting that endothelial dysfunction predicts atherosclerosis in COPD, but does not contribute to airflow limitation [42].

As a biomarker, GDF-15 has both strengths and limitations. Although GDF-15 appears to reflect an integrated stress response [15,37], understanding the significance of an elevated concentration is complicated by its production by multiple cell-types and in response to disparate stimuli [43]. Elevated GDF-15 may reflect endothelial cell dysfunction, common in advanced COPD and proposed as a shared pathway in CVD development [44]. However, endothelial dysfunction in COPD appears to relate in part to intrathoracic mechanics rather than inflammation [45], and may associate with specific COPD phenotypes [46]. Hence, GDF-15 might be elevated in individual COPD patients for diverse reasons. Thus, like TGF- $\beta$ itself, GDF-15 may not be simply good or bad, but either, depending on context, underlining the need for greater understanding of its signal transduction in specific cell-types and clinical settings.

Despite the strengths of a well-characterized cohort in which the CAC outcome has been validated [28], potential limitations include information bias, as coexistent diseases were self-reported. Although a significant concern for incident diseases, information bias is less so for prevalent diseases [47]. We attempted to improve the accuracy of excluding baseline CVD by supplementing self-reported diagnoses with history of related treatment or interventions. A second potential limitation is our use of a self-reported risk score to calculate future CHD likelihood, instead of biologic measures included in some common predictive instruments. However, the HEART score is a validated instrument specifically designed to use selfreported data in epidemiologic studies [29]. Finally, our cross-sectional design limits inferences about temporal associations. Nevertheless, we consider our findings robust, consistent with current understanding of associations between CHD and COPD and an advance in understanding the mechanisms involved in both diseases.

\section{Conclusions}

We demonstrate that in COPD subjects free of clinical CVD, subclinical atherosclerosis (measured as CAC on ungated HRCT) is frequent; and that GDF-15 contributes, independently of common cardiovascular risk factors and

Table 3 Multivariate models of association of GDF-15 with CAC score among different subgroups of COPDGene participants with COPD

\begin{tabular}{lllll}
\hline & \multicolumn{2}{l}{ Restricted to } & & \\
\cline { 2 - 5 } & $\begin{array}{l}\text { Female participants } \\
(n=327)\end{array}$ & $\begin{array}{l}\text { Participants without } \\
\text { diabetes }(n=634)\end{array}$ & $\begin{array}{l}\text { Participants not currently } \\
\text { smoking }(n=487)\end{array}$ & $\begin{array}{l}\text { Participants with no walking } \\
\text { limitation }(n=304)\end{array}$ \\
\hline $\begin{array}{l}\text { GDF-15 level (in tertiles) } \\
\text { Lower tertile }\end{array}$ & Ref. & Ref. & Ref. & Ref. \\
Intermediate tertile & $2.36(0.84,6.64)$ & $1.95(0.99,3.84)$ & $1.40(0.66,2.98)$ & $1.48(0.57,3.87)$ \\
Higher tertile & $4.56(1.62,12.8)$ & $4.00(2.06,7.78)$ & $2.41(1.13,5.12)$ & $3.76(1.63,10.4)$ \\
\hline
\end{tabular}

All entries represent risk ratio of being in the higher group of CAC and its $95 \% \mathrm{Cl}$, based on multinomial logistic regression models

All models additionally adjusted for race, GOLD spirometry stage, pack-years smoked, chronic bronchitis symptoms, history of exacerbations, and co-morbidities (asthma, GERD, mobility-related diseases) 
measures of COPD severity or phenotype, to its presence and severity.

\section{Additional file}

Additional file 1: Tables S1-S3. Table S1. Lack of association of GDF-15 levels or CAC score with PA:A ratio*. Table S2. Bivariate and Multivariate Associations with GDF-15 among COPDGene participants with COPD ( $n=694)$. Table S3. Multivariate models of association of GDF-15 with CAC score among different subgroups of COPDGene participants with COPD. (DOCX $33 \mathrm{~kb})$

\section{Abbreviations}

CAC: Coronary artery calcification; CHD: Coronary heart disease;

$\mathrm{Cl}$ : Confidence interval; COPD: Chronic obstructive pulmonary disease;

COPDGene: Genetic Epidemiology of COPD Study; CVD: Cardiovascular disease; GDF-15: Growth differentiation factor-15; GOLD: Global Initiative for Obstructive lung Disease; HEART: Personal heart early assessment risk tool; HRCT: High-resolution chest computed tomography; mMRC: Modified medical research council; NHANES: National health and nutrition examination survey; NT-proBNP: N-terminal pro-B-type natriuretic peptide; Pi10: The square root of the wall area of a theoretical airway of $10 \mathrm{~mm}$ luminal perimeter

\section{Acknowledgments}

The authors gratefully acknowledge the investigators and participants in the COPDGene study. The authors also acknowledge the assistance of Sara Penchev, Lori Stepp and Carla Wilson, National Jewish Health \& Research Center, Denver, CO.

\section{Availability of data and materials}

The following databases from the NHLBI-sponsored COPDGene study were used and are available to qualified investigators by submission of an ancillary study request to that study (copdgene.org): Final10000_Dataset_12MAR13.dta; CAC Budoff_07JUL14.dta; LFU_SidLevel_w Comorbid_31Aug15.dta. Data on the following biomarkers (GDF-15; troponin T; N-terminal-proBNP; and IL-6) are available from the corresponding author, by request.

\section{Authors' contributions}

JLC, CMF and MKH conceived and designed the study, contributed to the analysis and interpretation of data, and produced the first draft. CMF and JDN performed experiments. MJB measured coronary artery calcium scores. CHM, SM, XM, MKH performed statistical analyses. JMW FJM, EAR, EAK, MTD and FJM contributed to the design, analysis and interpretation of data, and drafting the article. All authors revised the article critically for important intellectual content and approved the final version.

\section{Competing interests}

Dr. Carlos H. Martinez has nothing to disclose. Dr. Freeman reports grants from Department of Veterans Affairs, during the conduct of the study; grants from Medlmmune, outside the submitted work. Mr. Nelson has nothing to disclose. Dr. Murray has nothing to disclose. Dr. Wang has nothing to disclose. Dr. Budoff reports grants from NIH during the conduct of the study; grants from General Electric, outside the submitted work. Dr. Dransfield reports grants from NHLBI during the conduct of the study; personal fees from Boehringer Ingelheim, GlaxoSmithKline, Genentech and Yungjin, and contracted clinical trials from Novartis, PneumRx, Pulmonx and Yungiin, outside the submitted work. Dr. Hokanson has nothing to disclose. Dr. Kazerooni has nothing to disclose. Dr. Kinney has nothing to disclose. Dr. Regan has nothing to disclose. Dr. Wells reports grants from $\mathrm{NIH} / \mathrm{NHLBI}$, contracted clinical trials from AstraZeneca, and GlaxoSmithKline, and consulting fees from AstraZeneca, all outside the submitted work. Dr. Fernando J. Martinez reports personal fees from Forest, Janssens, GSK, Nycomed/Takeda, Amgen, Astra Zeneca, Boehringer Ingelheim, Ikaria/Bellerophon, Genentech, GSK, Janssens, Novartis, Pearl, Pfizer, Roche, Sunovion, Theravance, Axon, GSK, CME Incite, California Society for Allergy and Immunology, Annenberg, Integritas, InThought, Miller Medical, National Association for Continuing Education, Paradigm, Peer Voice, UpToDate, Haymarket Communications, Astra Zeneca, Western Society of Allergy and Immunology from GSK, Informa, Bioscale, Unity Biotechnology, ConCert, Lucid,
Methodist Hospital, Prime, WebMD, and other from Mereo, during the conduct of the study; and personal fees, non-financial support and other from Boehringer Ingelheim, non-financial support and other from Centocor, non-financial support from Gilead, Genentech, Ikaria, personal fees and other from Boehringer Ingelheim, Kadmon, Nycomed/Takeda, Pfizer, Veracyte, American Thoracic Society, Academic CME, Falco, National Association for Continuing Education, Axon Communication, from Johnson \& Johnson, non-financial support from Biogen/Stromedix, grants from National Institutes of Health, Clarion, Continuing Education, Potomac, Afferent, Adept, outside the submitted work. Dr. Han reports personal fees from AstraZeneca, GSK, Boehringer Ingelheim, Novartis and UpToDate, and research support from Novartis, outside the submitted work. Dr. Curtis reports grants from NHLBI and the Department of Veterans Affairs, during the conduct of the study; grants from Medlmmune, outside the submitted work.

\section{Consent for publication}

This study does not report any individual subject data.

\section{Ethics approval and consent to participate}

Studies and consent procedures were performed in accordance with the Declaration of Helsinki. Participants understood the study purpose, and provided written informed consent before any procedures. Protocols were approved by Institutional Review Boards at VA Ann Arbor Healthcare System (FWA 00000348) and the University of Michigan (FWA 00004969), approval numbers 2010-120752, HUM000014973, respectively, where we conducted laboratory and statistical analysis, respectively, and at all participating clinical sites.

\section{Guarantor statement}

Dr. Curtis takes responsibility for the content of this manuscript, including data and analysis.

\section{Sources of support}

COPDGene is supported by NHLBI Grants R01 HL089897 and R01 HI089856. Additional support came from NIH Grants R01 HL122438-02S1 and K23 HL128936 (CHM) and R01 HL122438 (MKH); and from the Department of Veterans Affairs through Merit Review Awards 101 BX001389 (CMF) and 101 CX000911 (JLC). The contents of this publication are solely the responsibility of the authors and do not represent the official views of the National Institutes of Health or the Department of Veterans Affairs, who took no part in manuscript preparation.

\section{Author details}

${ }^{1}$ Division of Pulmonary \& Critical Care Medicine, University of Michigan Health System, 2215 Fuller Road, Ann Arbor, MI 48105-2303, USA. ${ }^{2}$ Research Service, VA Ann Arbor Healthcare System, Ann Arbor, MI, USA. ${ }^{3}$ Department of Biostatistics, School of Public Health, University of Michigan, Ann Arbor, MI, USA. ${ }^{4}$ Los Angeles Biomedical Research Institute at Harbor-UCLA Medical Center, Torrance, CA, USA. ${ }^{5}$ The Lung Health Center, Division of Pulmonary, Allergy \& Critical Care Medicine, University of Alabama at Birmingham, Birmingham, AL, USA. ${ }^{6}$ Medical Service, Birmingham Veteran Affairs Medical Center, Birmingham, AL, USA. ${ }^{7}$ School of Public Health, University of Colorado, Aurora, CO, USA. ${ }^{8}$ Radiology Department, University of Michigan Health System, Ann Arbor, MI, USA. ${ }^{9}$ National Jewish Health \& Research Center, Denver, CO, USA. ${ }^{10}$ Pulmonary \& Critical Care Medicine Division, Department of Medicine, University of Colorado, Denver, CO, USA.

${ }^{11}$ Pulmonary \& Critical Care Medicine Division, Department of Medicine, Weill Cornell Medical College, New York, NY, USA. ${ }^{12}$ Graduate Program in Immunology, University of Michigan, 2215 Fuller Road, Ann Arbor, M 48105-2303, USA. ${ }^{13}$ Medical Service, VA Ann Arbor Healthcare System, 2215 Fuller Road, Ann Arbor, MI 48105-2303, USA.

Received: 29 November 2016 Accepted: 13 February 2017 Published online: 28 February 2017

\section{References}

1. Mannino DM, Thorn D, Swensen A, Holguin F. Prevalence and outcomes of diabetes, hypertension and cardiovascular disease in COPD. Eur Respir J. 2008:32:962-9

2. Sidney S, Sorel M, Quesenberry Jr CP, DeLuise C, Lanes S, Eisner MD. COPD and incident cardiovascular disease hospitalizations and mortality: Kaiser Permanente Medical Care Program. Chest. 2005;128:2068-75. 
3. Rohatgi A, Patel P, Das SR, Ayers CR, Khera A, Martinez-Rumayor A, Berry JD, McGuire DK, de Lemos JA. Association of growth differentiation factor-15 with coronary atherosclerosis and mortality in a young, multiethnic population: observations from the Dallas Heart Study. Clin Chem. 2012;58:172-82.

4. Feary JR, Rodrigues LC, Smith CJ, Hubbard RB, Gibson JE. Prevalence of major comorbidities in subjects with COPD and incidence of myocardial infarction and stroke: a comprehensive analysis using data from primary care. Thorax. 2010;65:956-62.

5. Agarwal S, Rokadia H, Senn T, Menon V. Burden of cardiovascular disease in chronic obstructive pulmonary disease. Am J Prev Med. 2014;47:105-14.

6. Landis SH, Muellerova H, Mannino DM, Menezes AM, Han MK, van der Molen T, Ichinose M, Aisanov Z, Oh YM, Davis KJ. Continuing to Confront COPD International Patient Survey: methods, COPD prevalence, and disease burden in 2012-2013. Int J Chron Obstruct Pulmon Dis. 2014;9:597-611.

7. Adeloye D, Chua S, Lee C, Basquill C, Papana A, Theodoratou E, Nair H, Gasevic D, Sridhar D, Campbell H, Chan KY, Sheikh A, Rudan I, Global Health Epidemiology Reference Group (GHERG). Global and regional estimates of COPD prevalence: Systematic review and meta-analysis. J Glob Health. 2015;5:020415.

8. Aryal S, Diaz-Guzman E, Mannino DM. Influence of sex on chronic obstructive pulmonary disease risk and treatment outcomes. Int J Chron Obstruct Pulmon Dis. 2014:9:1145-54.

9. Parker DR, Liu J, Roberts MB, Eaton CB. Is inflammatory chronic obstructive pulmonary disease a coronary heart disease risk equivalent? A longitudinal analysis of the third National Health and Nutrition Examination Survey (NHANES III), 1988-1994. BMC Pulm Med. 2014;14:195.

10. Wilker EH, Alexeeff SE, Poon A, Litonjua AA, Sparrow D, Vokonas PS, Mittleman MA, Schwartz J. Candidate genes for respiratory disease associated with markers of inflammation and endothelial dysfunction in elderly men. Atherosclerosis. 2009;206:480-5.

11. Budoff MJ, Hokanson JE, Nasir K, Shaw L, Kinney GL, Chow D, Demoss D, Nuguri V, Nabavi V, Ratakonda R, Berman DS, Raggi P. Progression of coronary artery calcium predicts all-cause mortality. JACC Cardiovasc Imaging. 2010;3:1229-36.

12. Raggi $\mathrm{P}$, Gongora MC, Gopal A, Callister TQ, Budoff M, Shaw L. Coronary artery calcium to predict all-cause mortality in elderly men and women. J Am Coll Cardiol. 2008;52:17-23.

13. Izumiya Y, Hanatani S, Kimura Y, Takashio S, Yamamoto E, Kusaka H, Tokitsu T, Rokutanda T, Araki S, Tsujita K, Tanaka T, Yamamuro M, Kojima S, Tayama S, Kaikita K, Hokimoto S, Ogawa H. Growth differentiation factor-15 is a useful prognostic marker in patients with heart failure with preserved ejection fraction. Can J Cardiol. 2014;30:338-44

14. Daniels LB, Clopton P, Laughlin GA, Maisel AS, Barrett-Connor E. Growthdifferentiation factor-15 is a robust, independent predictor of 11-year mortality risk in community-dwelling older adults: the Rancho Bernardo Study. Circulation. 2011:123:2101-10.

15. Eggers KM, Kempf T, Wallentin L, Wollert KC, Lind L. Change in growth differentiation factor 15 concentrations over time independently predicts mortality in community-dwelling elderly individuals. Clin Chem. 2013;59:1091-8.

16. Kim M, Cha SI, Choi KJ, Shin KM, Lim JK, Yoo SS, Lee J, Lee SY, Kim CH, Park JY, Yang DH. Prognostic value of serum growth differentiation factor-15 in patients with chronic obstructive pulmonary disease exacerbation. Tuberc Respir Dis (Seoul). 2014;77:243-50.

17. Freeman CM, Martinez CH, Todt JC, Martinez FJ, Han MK, Thompson DL, McCloskey L, Curtis JL. Acute exacerbations of chronic obstructive pulmonary disease are associated with decreased CD4+ \& CD8+ T cells and increased growth \& differentiation factor-15 (GDF-15) in peripheral blood. Respir Res. 2015;16:94.

18. Mutlu LC, Altintas N, Aydin M, Tulubas F, Oran M, Kucukyalin V, Kaplan G, Gurel A. Growth Differentiation Factor-15 is a novel biomarker predicting acute exacerbation of chronic obstructive pulmonary disease. Inflammation. 2015;445:155-60.

19. Han MK, Agusti A, Calverley PM, Celli BR, Criner G, Curtis JL, Fabbri LM, Goldin JG, Jones PW, Macnee W, Make BJ, Rabe KF, Rennard SI, Sciurba FC, Silverman EK, Vestbo J, Washko GR, Wouters EF, Martinez FJ. Chronic obstructive pulmonary disease phenotypes: the future of COPD. Am J Respir Crit Care Med. 2010:182:598-604.

20. Martinez $\mathrm{CH}$, Han MK. Contribution of the environment and comorbidities to chronic obstructive pulmonary disease phenotypes. Med Clin North Am. 2012;96:713-27.

21. Hersh CP, Make BJ, Lynch DA, Barr RG, Bowler RP, Calverley PM, Castaldi PJ, Cho MH, Coxson HO, DeMeo DL, Foreman MG, Han MK, Harshfield BJ,
Hokanson JE, Lutz S, Ramsdell JW, Regan EA, Rennard SI, Schroeder JD, Sciurba FC, Steiner RM, Tal-Singer R, van Beek Jr E, Silverman EK, Crapo JD, COPDGene Investigators. Non-emphysematous chronic obstructive pulmonary disease is associated with diabetes mellitus. BMC Pulm Med. 2014;14:164.

22. Regan EA, Hokanson JE, Murphy JR, Make B, Lynch DA, Beaty TH, Curran-Everett D, Silverman EK, Crapo JD. Genetic epidemiology of COPD (COPDGene) study design. COPD. 2010;7:32-43.

23. Vestbo J, Hurd SS, Agusti AG, Jones PW, Vogelmeier C, Anzueto A, Barnes PJ, Fabbri LM, Martinez FJ, Nishimura M, Stockley RA, Sin DD, Rodriguez-Roisin R. Global strategy for the diagnosis, management, and prevention of chronic obstructive pulmonary disease: GOLD executive summary. Am J Respir Crit Care Med. 2013;187:347-65.

24. Hankinson JL, Odencrantz JR, Fedan KB. Spirometric reference values from a sample of the general U.S. population. Am J Respir Crit Care Med. 1999:159:179-87.

25. Budoff MJ, Achenbach S, Blumenthal RS, Carr JJ, Goldin JG, Greenland P, Guerci AD, Lima JA, Rader DJ, Rubin GD, Shaw $L$, Wiegers SE, American Heart Association Committee on Cardiovascular I, Intervention, American Heart Association Council on Cardiovascular R, Intervention, American Heart Association Committee on Cardiac Imaging CoCC. Assessment of coronary artery disease by cardiac computed tomography: a scientific statement from the American Heart Association Committee on Cardiovascular Imaging and Intervention, Council on Cardiovascular Radiology and Intervention, and Committee on Cardiac Imaging, Council on Clinical Cardiology. Circulation. 2006;114:1761-91.

26. Agatston AS, Janowitz WR, Hildner FJ, Zusmer NR, Viamonte Jr M, Detrano R. Quantification of coronary artery calcium using ultrafast computed tomography. J Am Coll Cardiol. 1990;15:827-32.

27. Williams MC, Murchison JT, Edwards LD, Agusti A, Bakke P, Calverley PM, Celli B, Coxson HO, Crim C, Lomas DA, Miller BE, Rennard S, Silverman EK, Tal-Singer R, Vestbo J, Wouters E, Yates JC, van Beek EJ, Newby DE, MacNee W. Coronary artery calcification is increased in patients with COPD and associated with increased morbidity and mortality. Thorax. 2014;69:718-23.

28. Budoff MJ, Nasir K, Kinney GL, Hokanson JE, Barr RG, Steiner R, Nath H, Lopez-Garcia C, Black-Shinn J, Casaburi R. Coronary artery and thoracic calcium on noncontrast thoracic $C T$ scans: comparison of ungated and gated examinations in patients from the COPDGene cohort. J Cardiovasc Comput Tomogr. 2011;5:113-8.

29. Mainous 3rd AG, Koopman RJ, Diaz VA, Everett CJ, Wilson PW, Tilley BC. A coronary heart disease risk score based on patient-reported information. Am J Cardiol. 2007:99:1236-41.

30. Wells JM, Washko GR, Han MK, Abbas N, Nath H, Mamary AJ, Regan E, Bailey WC, Martinez FJ, Westfall E, Beaty TH, Curran-Everett D, Curtis JL, Hokanson JE, Lynch DA, Make BJ, Crapo JD, Silverman EK, Bowler RP, Dransfield MT. Pulmonary arterial enlargement and acute exacerbations of COPD. N Engl J Med. 2012;367:913-21.

31. Schopfer DW, Ku IA, Regan M, Whooley MA. Growth differentiation factor 15 and cardiovascular events in patients with stable ischemic heart disease (The Heart and Soul Study). Am Heart J. 2014;167:186-192.e181.

32. Hole DJ, Watt GC, Davey-Smith G, Hart CL, Gillis CR, Hawthorne VM. Impaired lung function and mortality risk in men and women: findings from the Renfrew and Paisley prospective population study. BMJ. 1996; 313:711-5.

33. Iwamoto H, Yokoyama A, Kitahara Y, Ishikawa N, Haruta Y, Yamane K, Hattori N, Hara H, Kohno N. Airflow limitation in smokers is associated with subclinical atherosclerosis. Am J Respir Crit Care Med. 2009;179:35-40.

34. Folsom AR, Kronmal RA, Detrano RC, O'Leary DH, Bild DE, Bluemke DA, Budoff MJ, Liu K, Shea S, Szklo M, Tracy RP, Watson KE, Burke GL. Coronary artery calcification compared with carotid intima-media thickness in the prediction of cardiovascular disease incidence: the Multi-Ethnic Study of Atherosclerosis (MESA). Arch Intern Med. 2008;168:1333-9.

35. Wu Q, Jiang $\mathrm{D}$, Chu HW. Cigarette smoke induces growth differentiation factor 15 production in human lung epithelial cells: Implication in mucin over-expression. Innate Immun. 2011:18:617-626.

36. Wollert KC, Kempf T, Peter T, Olofsson S, James S, Johnston N, Lindahl B, Horn-Wichmann R, Brabant G, Simoons ML, Armstrong PW, Califf RM, Drexler $\mathrm{H}$, Wallentin L. Prognostic value of growth-differentiation factor-15 in patients with non-ST-elevation acute coronary syndrome. Circulation. 2007:115:962-71.

37. Kempf T, von Haehling $S$, Peter T, Allhoff T, Cicoira M, Doehner W, Ponikowski P, Filippatos GS, Rozentryt P, Drexler H, Anker SD, Wollert KC. 
Prognostic utility of growth differentiation factor-15 in patients with chronic heart failure. J Am Coll Cardiol. 2007;50:1054-60.

38. Mueller T, Leitner I, Egger M, Haltmayer M, Dieplinger B. Association of the biomarkers soluble ST2, galectin-3 and growth-differentiation factor-15 with heart failure and other non-cardiac diseases. Clin Chim Acta. 2015;445:155-60.

39. Lind L, Wallentin L, Kempf T, Tapken H, Quint A, Lindahl B, Olofsson S, Venge P, Larsson A, Hulthe J, Elmgren A, Wollert KC. Growth-differentiation factor-15 is an independent marker of cardiovascular dysfunction and disease in the elderly: results from the Prospective Investigation of the Vasculature in Uppsala Seniors (PIVUS) Study. Eur Heart J. 2009:30:2346-53.

40. Greenland P, Bonow RO, Brundage BH, Budoff MJ, Eisenberg MJ, Grundy SM, Lauer MS, Post WS, Raggi P, Redberg RF, et al. ACCF/AHA 2007 clinical expert consensus document on coronary artery calcium scoring by computed tomography in global cardiovascular risk assessment and in evaluation of patients with chest pain: a report of the American College of Cardiology Foundation Clinical Expert Consensus Task Force (ACCF/AHA Writing Committee to Update the 2000 Expert Consensus Document on Electron Beam Computed Tomography). Circulation. 2007;115:402-26.

41. Gaisl T, Schlatzer C, Schwarz El, Possner M, Stehli J, Sievi NA, Clarenbach CF, Dey D, Slomka PJ, Kaufmann PA, Kohler M. Coronary artery calcification, epicardial fat burden, and cardiovascular events in chronic obstructive pulmonary disease. PLoS ONE. 2015;10:e0126613.

42. Chandra D, Gupta A, Strollo Jr PJ, Fuhrman CR, Leader JK, Bon J, Slivka WA Shoushtari AH, Avolio J, Kip KE, Reis S, Sciurba FC. Airflow limitation and endothelial dysfunction: Unrelated and independent predictors of atherosclerosis. Am J Respir Crit Care Med. 2016;194:38-47.

43. Unsicker K, Spittau B, Krieglstein K. The multiple facets of the TGF-beta family cytokine growth/differentiation factor-15/macrophage inhibitory cytokine-1. Cytokine Growth Factor Rev. 2013;24:373-84.

44. Urban MH, Valipour A, Kiss D, Eickhoff P, Funk GC, Burghuber OC. Soluble receptor of advanced glycation end-products and endothelial dysfunction in COPD. Respir Med. 2014;108:891-7.

45. Clarenbach CF, Sievi NA, Brock M, Schneiter D, Weder W, Kohler M. Lung volume reduction surgery and improvement of endothelial function and blood pressure in patients with chronic obstructive pulmonary disease. A randomized controlled trial. Am J Respir Crit Care Med. 2015;192:307-14.

46. Hueper K, Vogel-Claussen J, Parikh MA, Austin JH, Bluemke DA, Carr J, Choi J, Goldstein TA, Gomes AS, Hoffman EA, Kawut SM, Lima J, Michos ED, Post WS, Po MJ, Prince MR, Liu K, Rabinowitz D, Skrok J, Smith BM, Watson K, Yin Y, Zambeli-Ljepovic AM, Barr RG. Pulmonary microvascular blood flow in mild chronic obstructive pulmonary disease and emphysema. The MESA COPD Study. Am J Respir Crit Care Med. 2015;192:570-80.

47. Oksanen T, Kivimaki M, Pentti J, Virtanen M, Klaukka T, Vahtera J. Self-report as an indicator of incident disease. Ann Epidemiol. 2010;20:547-54.

\section{Submit your next manuscript to BioMed Central and we will help you at every step:}

- We accept pre-submission inquiries

- Our selector tool helps you to find the most relevant journal

- We provide round the clock customer support

- Convenient online submission

- Thorough peer review

- Inclusion in PubMed and all major indexing services

- Maximum visibility for your research

Submit your manuscript at www.biomedcentral.com/submit

) Biomed Central 